\title{
Inhibitory Properties of Neomycin Thin Film Formed on Carbon Steel in Sulfuric Acid Solution: Electrochemical and AFM Investigation
}

\author{
Adriana Samide ${ }^{1, *}$, Gabriela Eugenia Iacobescu ${ }^{2}$, Bogdan Tutunaru ${ }^{1}$, Roxana Grecu ${ }^{1}$, \\ Cristian Tigae ${ }^{1}$ and Cezar Spînu ${ }^{1}$ \\ 1 Department of Chemistry, Faculty of Sciences, University of Craiova, Calea Bucuresti 107i, \\ Craiova 200478, Romania; tutunaruchim@yahoo.com (B.T.); roxanamarius2008@yahoo.com (R.G.); \\ ctigae@yahoo.com(C.T.); spinu_cezar@yahoo.com (C.S.) \\ 2 Department of Physics, Faculty of Sciences, University of Craiova, A.I. Cuza No. 1, \\ Craiova 200585, Romania; gabrielaiacobescu@yahoo.com \\ * Correspondence: samide.adriana@ucv.ro; Tel.: +40-251-597-048
}

Academic Editor: Giovanni Zangari

Received: 11 August 2017; Accepted: 25 October 2017; Published: 31 October 2017

\begin{abstract}
Our study aims to implement a strategy to reduce the carbon steel corrosion rate in a sulfuric acid solution, using an expired drug with adsorption affinity on the metal surface. To investigate the corrosion protection efficiency of an environmental friendly inhibitor, namely neomycin sulfate (NMS), the electrochemical measurements were applied on carbon steel immersed in $1.0 \mathrm{M} \mathrm{H}_{2} \mathrm{SO}_{4}$ solution with and without NMS. The protective layer that formed on the steel surface was studied by atomic force microscopy (AFM). The potentiodynamic polarization and electrochemical impedance spectroscopy (EIS) showed that the presence of the neomycin sulfate in acid solution leads to the decrease in corrosion current density $\left(i_{\text {corr }}\right)$ and the increase of polarization resistance $\left(R_{\mathrm{p}}\right)$. The mixed mechanism between physical and chemical adsorption of NMS molecules on the steel surface was proposed according to the Langmuir adsorption isotherm. AFM indicated that the NMS molecules contributed to a protective layer formation by their adsorption on the steel surface. The AFM parameters, such as root mean square roughness $\left(R_{\mathrm{q}}\right)$, average roughness $\left(R_{\mathrm{a}}\right)$, and maximum peak to valley height $\left(R_{\mathrm{p}-\mathrm{v}}\right)$ revealed that in the presence of NMS a smoother surface of carbon steel was obtained, compared to the steel surface corroded in sulfuric acid blank solution.
\end{abstract}

Keywords: expired drug; corrosion inhibitor; potentiodynamic polarization; electrochemical impedance spectroscopy; AFM

\section{Introduction}

The different types of steel are widely utilized in many industrial fields due to their specific characteristics and properties. The lifetime of steel is influenced by the chemical or electrochemical reactions which take place at metallic material/environment interface. The carbon steel is used for the manufacturing of some industrial systems, such as pipes, pumps, turbine blades, and water coolers and heaters. The contact with acidic/alkaline media leads to steel corrosion due to the oxidation reactions, its surface being partially or totally affected.

The corrosion control and prevention involve the use of effective methods to protect the metal surfaces. The change of the environment composition by the addition of some corrosion inhibitors represents an appropriate way to modify the contact interface between metal surface and electrolyte. The organic compounds act by adsorption on surface, forming protective layers with inhibitory properties against metal oxidation. The molecules of organic compounds contain oxygen, nitrogen, 
and sulfur heteroatoms with high adsorption affinity on the metallic surfaces [1-8]. Thus, organic substances act by physical or chemical adsorption on the metal surface involving electrostatic interactions, physical or chemical bonds between unshared electron pairs of the heteroatoms and the $d$-vacant orbital of some metal atoms from surface [2-6].

Many types of compounds [2-13], such as drugs [2-9], plant extracts [10,13] and polymers [11,12], have been reported as efficient corrosion inhibitors that can contribute to the formation of protective layers on the carbon steel/stainless steel surfaces. The use of expired drugs in other activity fields could lead to the reduction of their disposal/destroying costs. A proper method is their reintegration into the chemical industry, as "green corrosion inhibitors" for metallic materials [4-9,14,15], being less toxic than others, having aqueous solubility and adsorption affinity for the metal surface, and/or the capacity to form complexes with the metal ions released in solution during corrosion processes [4-8].

The weight loss method and electrochemical measurements, coupled with different techniques, such as scanning electron microscopy (SEM), X-ray photoelectron spectroscopy (XPS), UV-Vis spectrophotometry, high-performance liquid chromatography (HLPC), and thermal analysis, have been used [2,4-8] to evaluate the inhibitory performance of some drugs for carbon steel corrosion in hydrochloric acid solution. Thus, for trimethoprim [2], quinine sulfate [4], aminophylline [5], sulfacetamide [6], and sulfathiazole [7,8] the inhibition efficiency (IE) reached values between $80.0 \%$ and $93.0 \%$, depending on their concentrations in the studied environment. The XPS can accurately reveal the metal surface layer composition, both in the absence and presence of the inhibitor. From the high-resolution XPS spectra, the binding energy can be determined and attributed to the corrosion products (oxides, hydroxides, oxy-hydroxides) and other bonds between atoms/heteroatoms from the molecules of the organic compounds. Thus, the change of surface layer composition due to the adsorption of some organic molecules can be highlighted $[7,8]$.

Some expired drugs have also been used as corrosion inhibitors for other metals, such as copper, aluminum, and alloys. The metronidazole drug presented high performance as a corrosion inhibitor for copper in $1.0 \mathrm{M} \mathrm{HCl}$ solution [14]. Penicillins, cephalosporins, aminoglycosides, azoles, and other drugs were the most studied compounds as corrosion inhibitors for aluminum and its alloys in various solutions $[15,16]$.

Recently, the use of neomycin as a corrosion inhibitor for stainless steel in $2.0 \mathrm{M} \mathrm{H}_{2} \mathrm{SO}_{4}$ solution [17], for carbon steel in $1.0 \mathrm{M} \mathrm{HCl}$ solution [18], and for mild steel in a chloride environment [19], has been reported. The inhibition efficiency of this drug was calculated according to the weight loss and electrochemical measurements. Raja et al. [17] proved that neomycin behaves as a corrosion inhibitor for 304 stainless steel in sulfuric acid solution, reaching an inhibition efficiency of about $89.0 \%$, at its concentration of $3.0 \mathrm{mM}$, calculated from the mass loss method, the potentiodynamic polarization and the electrochemical impedance spectroscopy. Fouda et al. [18] have studied the behavior of the neomycin sulfate as corrosion inhibitor for carbon steel in $1.0 \mathrm{M} \mathrm{HCl}$ solution using chemical and electrochemical measurements, yielding from EIS, an inhibition efficiency value of $81.7 \%$, the inhibitor concentration being of $15 \times 10^{-6} \mathrm{M}$. They conclude that the neomycin acted by adsorption, mainly due to electrostatic interactions between the inhibitor molecules and the steel surface. Chitra and Anand [19] calculated an inhibition efficiency of $75.1 \%$ for mild steel corrosion in $2.0 \mathrm{M} \mathrm{KCl}$ solution containing $0.5 \mathrm{mM}$ neomycin using the mass loss method. The FTIR spectral study showed that the protective deposit consisted of a metal-neomycin complex. The IR adsorption peaks were attributed to some functional groups as $(-\mathrm{OH})$ or bonds, such as, $\mathrm{C}-\mathrm{H}, \mathrm{C}-\mathrm{N}, \mathrm{C}=\mathrm{C}$, and $\mathrm{C}-\mathrm{O}$ of the inhibitor molecules adsorbed on the steel surface [19].

In the present work, the effect of neomycin sulfate (NMS), with the molecular formula $\mathrm{C}_{23} \mathrm{H}_{46} \mathrm{~N}_{6} \mathrm{O}_{13} \times \mathrm{H}_{2} \mathrm{SO}_{4}$, on carbon steel corrosion inhibition in $1.0 \mathrm{M} \mathrm{H}_{2} \mathrm{SO}_{4}$ was investigated using potentiodynamic polarization and electrochemical impedance spectroscopy (EIS). Moreover, the changes appeared in the surface morphology, and the protective layer characteristics formed by adsorption of NMS molecules were studied by atomic force microscopy (AFM). 


\section{Experimental}

\subsection{Materials}

The carbon steel plates, with an area of $1.0 \mathrm{~cm}^{2}$, and the following composition (wt \%): $\mathrm{C}=0.1 \%$; $\mathrm{Si}=0.035 \% ; \mathrm{Mn}=0.4 \% ; \mathrm{Cr}=0.3 \% ; \mathrm{Ni}=0.3 \%$; Fe in balance, were submitted to corrosion in $1.0 \mathrm{M} \mathrm{H}_{2} \mathrm{SO}_{4}$ solution. Before corrosion, the samples were mechanically polished with emery paper, ultrasonically cleaned, degreased with ethyl alcohol, and dried in warm air. The corrosion tests were performed in $1.0 \mathrm{M} \mathrm{H}_{2} \mathrm{SO}_{4}$ blank solution and $1.0 \mathrm{M} \mathrm{H}_{2} \mathrm{SO}_{4}$ solution containing various neomycin concentrations: $0.3 \mathrm{mM} ; 0.5 \mathrm{mM} ; 0.7 \mathrm{mM} ; 0.9 \mathrm{mM}$. All reagents with adequate chemical purity were purchased from Sigma Aldrich (St. Louis, MO, USA).

\subsection{Electrochemical Measurements}

Both potentiodynamic polarization and electrochemical impedance spectroscopy (EIS) were accomplished on carbon steel in $1.0 \mathrm{M} \mathrm{H}_{2} \mathrm{SO}_{4}$ solution without and with various NMS concentrations using an electrochemical system VoltaLab VoltaMaster 4 software (version 7.8.26338.3). An open space electrochemical cell with three electrodes was used. The working electrode was manufactured from carbon steel plates with the area of $1.0 \mathrm{~cm}^{2}$. A foil of platinum (area of $1.0 \mathrm{~cm}^{2}$ ) and an $\mathrm{Ag} / \mathrm{AgCl}$ electrode were used as auxiliary and reference electrodes, respectively.

The potentiodynamic polarization was conducted at the room temperature $\left(23 \pm 1^{\circ} \mathrm{C}\right)$ with the potential scan rate of $1.0 \mathrm{mV} \cdot \mathrm{s}^{-1}$, between $-1000 \mathrm{mV}$ and $100 \mathrm{mV}$, after $4.0 \mathrm{~min}$ of pre-polarization time of electrodes at open circuit. The potentiodynamic curves were processed as semi-log curves in the range of $\pm 250 \mathrm{mV}$ with respect to the corrosion potential ( $\left.E_{\text {corr }}\right)$. The corrosion current density $\left(i_{\text {corr }}\right)$ was computed to the intersection of Tafel lines, at the corrosion potential. Also, to determine the polarization resistance $\left(R_{\mathrm{p}}\right)$, the potentiodynamic polarization curves were processed in a range close to the $E_{\text {corr }}( \pm 20 \mathrm{mV})$, where $i$ vs. $E$ plots represent straight lines with the slopes equal to $1 / R_{\mathrm{p}}$.

Before and after the potentiodynamic polarization, the UV-Vis spectrophotometric analysis of $1.0 \mathrm{M} \mathrm{H}_{2} \mathrm{SO}_{4}$ solution containing $0.9 \mathrm{mM}$ neomycin was carried out in the wavelength range from $800 \mathrm{~nm}$ to $200 \mathrm{~nm}$. The UV-Vis spectrophotometer, a Varian-Cary 50 type (Varian Inc., Mulgrave, VIC, Australia), with Cary WinUV software, version 3.0(303) was used to obtain the analysis reports.

EIS was recorded as Nyquist and Bode diagrams in the frequency range of $10^{5} \mathrm{~Hz}$ and $10^{-1} \mathrm{~Hz}$, with an amplitude signal of $10 \mathrm{mV}$, at room temperature $\left(23 \pm 1^{\circ} \mathrm{C}\right)$ after $4.0 \mathrm{~min}$ of relaxation time of the electrodes, in an open circuit.

\subsection{Atomic Force Microscopy (AFM) Measurements}

The surface morphologies of the carbon steel control sample and carbon steel corroded in $1.0 \mathrm{M}$ $\mathrm{H}_{2} \mathrm{SO}_{4}$ blank solution and in $1.0 \mathrm{M} \mathrm{H}_{2} \mathrm{SO}_{4}$ solution containing $0.9 \mathrm{mM} \mathrm{NMS}$ were studied by non-contact mode atomic force microscopy (NC-AFM, Park Systems, Suwon, Korea), PARK XE-100 SPM system). The cantilever had a nominal length of $125 \mathrm{~mm}$, a nominal force constant of $40 \mathrm{~N} / \mathrm{m}$, and oscillation frequencies in the range of $275-373 \mathrm{kHz}$. We used horizontal line by line flattening as the planarization method. The average roughness $\left(R_{\mathrm{a}}\right)$, root mean square (RMS) roughness $\left(R_{\mathrm{q}}\right)$, and maximum peak to valley height $\left(R_{\mathrm{p}-\mathrm{v}}\right)$ of the surfaces were estimated over the areas of $45 \mu \mathrm{m} \times 45 \mu \mathrm{m}$.

\section{Results and Discussion}

\subsection{Potentiodynamic Polarization}

The results of potentiodynamic polarization are presented in Figure 1. The potentiodynamic curves were processed as semi-log curves (Figure 1a) from which the corrosion current density $\left(i_{\text {corr }}\right)$ was determined by applying the system of Tafel Equations (1) and (2) for anodic and cathodic processes. The polarization resistance $\left(R_{\mathrm{p}}\right)$ was calculated from the linear shapes of polarization curves recorded 
close to $E_{\text {corr }}$, in the potential range of $\pm 20 \mathrm{mV}$ (Figure $1 \mathrm{~b}$ ), the corrosion current density ( $\left.i_{\text {corr }}\right)$ being computed by applying the Stern Geary equation (Equation (3)):

$$
\begin{aligned}
\eta & =b_{\mathrm{a}} \lg i-b_{\mathrm{a}} \lg i_{\text {corr }} \\
\eta & =b_{\mathrm{c}} \lg i_{\text {corr }}-b_{\mathrm{c}} \lg i \\
i_{\text {corr }} & =\frac{b_{\mathrm{a}} \cdot b_{\mathrm{c}}}{2.303\left(b_{\mathrm{a}}+b_{\mathrm{c}}\right)} \cdot \frac{1}{R_{\mathrm{P}}}
\end{aligned}
$$

where $\eta$ is over-voltage; $b_{\mathrm{a}}$ and $b_{\mathrm{c}}$ are Tafel anodic and cathodic slopes; and $i_{\text {corr }}$ and $R_{\mathrm{p}}$ are corrosion current density and polarization resistance, respectively.

From Figure 1a, it can be seen that the addition of NMS leads to: (i) the shifting of curves to higher potential values for all NMS concentrations, which entails the increase of the corrosion potential $\left(E_{\text {corr }}\right)$ in proportion to the increase in drug concentration; (ii) the movement of the polarization curves in lower current areas highlights the decrease in corrosion current density $\left(i_{\text {corr }}\right)$ with the NMS concentration increase; and (iii) the addition of NMS in $1.0 \mathrm{M} \mathrm{H}_{2} \mathrm{SO}_{4}$, solution affects the anodic process more than the cathodic one and, consequently, NMS acts as a mixed inhibitor, predominantly anodic, indicating the occurrence of a protective film [20] on the carbon steel surface that leads to the decrease of the corrosion current density.
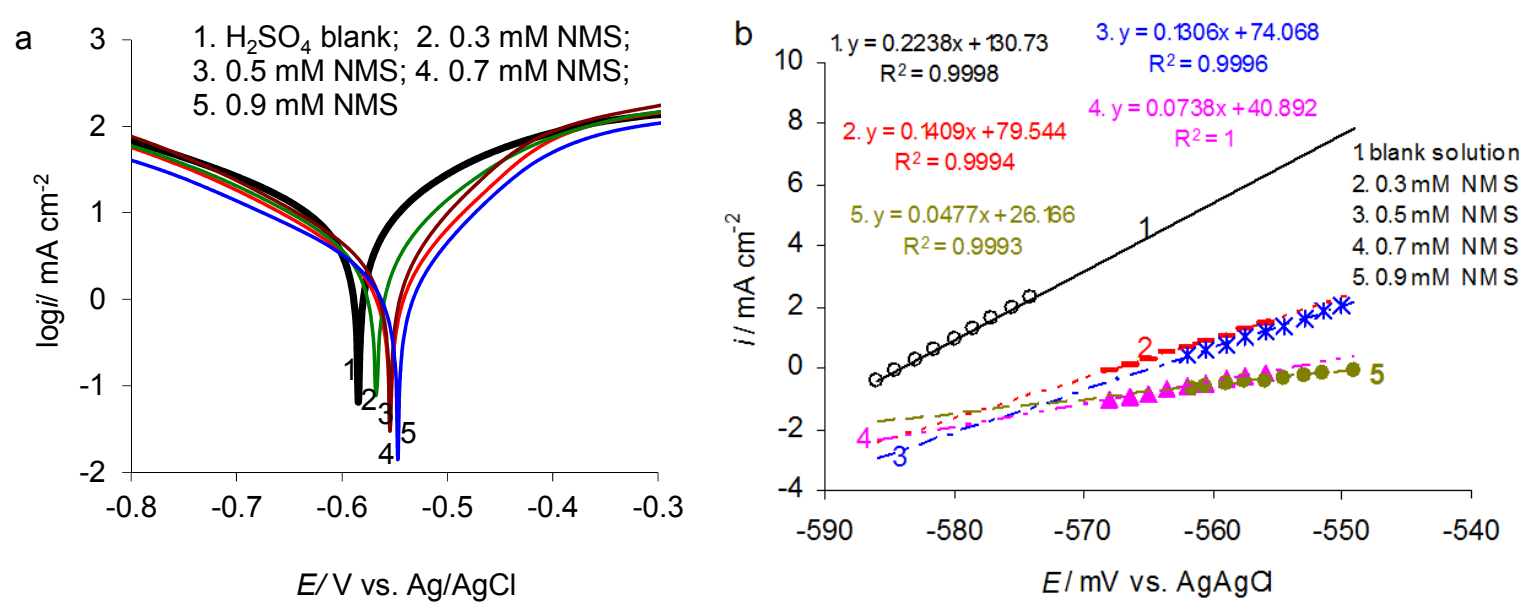

Figure 1. The potentiodynamic polarization curves recorded for carbon steel corroded in $1.0 \mathrm{M} \mathrm{H}_{2} \mathrm{SO}_{4}$, in the absence and in the presence of NMS: (a) Tafel diagram; and (b) linear diagram obtained in the potential range of $\pm 20 \mathrm{mV}$ around $E_{\text {corr. }}$.

The main electrochemical parameters were calculated using VoltaMaster 4 software and these are listed in Table 1. From the straight lines (Figure 1b) drawn in the potential range of $\pm 20 \mathrm{mV}$, close to the corresponding $E_{\mathrm{corr}}$, the polarization resistance $\left(R_{\mathrm{p}}\right)$ was determined according to Equation (4) [14]:

$$
1 / R_{\mathrm{p}}=(\mathrm{d} i / \mathrm{d} E)_{E \rightarrow E_{\text {corr }}}
$$

where (di/dE) $E \rightarrow E_{\text {corr }}$ represents the slope of the straight lines shown in Figure 1b.

The slopes of straight lines were calculated by deriving the equations inserted in the graph from Figure 1b. A gradual increase of the polarization resistance is noticed, from $4.4 \Omega \cdot \mathrm{cm}^{2}$ for the uninhibited solution to $20.9 \Omega \cdot \mathrm{cm}^{2}$ for the solution containing $0.9 \mathrm{mM}$ neomycin, thus confirming the protective film formation [14] on the steel surface. 
Table 1. The effect of the NMS concentration on the electrochemical parameters obtained from potentiodynamic polarization and EIS and its average inhibition efficiency (IE) for carbon steel corrosion in $1.0 \mathrm{M} \mathrm{H}_{2} \mathrm{SO}_{4}$ solution at the room temperature.

\begin{tabular}{|c|c|c|c|c|c|c|c|c|}
\hline \multirow{2}{*}{$C$-NMS/mM } & \multirow{2}{*}{$\begin{array}{c}E_{\text {corr }} / \mathrm{mV} \text { vs. } \\
\mathrm{Ag} / \mathrm{AgCl}\end{array}$} & \multirow{2}{*}{$i_{\text {corr }} / \mu \mathrm{A} \cdot \mathrm{cm}^{-2}$} & \multirow{2}{*}{$C_{\mathrm{dl}} / \mu \mathrm{F} \cdot \mathrm{cm}^{-2}$} & \multirow{2}{*}{$n$} & \multirow{2}{*}{$R_{\mathrm{ct}} / \Omega \cdot \mathrm{cm}^{2}$} & \multicolumn{3}{|c|}{ IE/\% } \\
\hline & & & & & & From Tafel & From EIS & Average Values \\
\hline 0 & -584.5 & 1560 & 520 & 0.963 & 5.3 & - & - & - \\
\hline 0.5 & -554.5 & 540 & 225 & 0.979 & 16.6 & 65.4 & 68.1 & $66.8 \pm 1.3$ \\
\hline 0.7 & -554.0 & 460 & 197 & 0.975 & 17.2 & 70.5 & 69.2 & $69.9 \pm 07$ \\
\hline 0.9 & -547.0 & 320 & 165 & 0.968 & 19.8 & 79.5 & 73.2 & $76.4 \pm 3.2$ \\
\hline
\end{tabular}

\subsection{Electrochemical Impedance Spectroscopy (EIS)}

Electrochemical impedance spectroscopy (EIS) was applied on carbon steel surface in $1.0 \mathrm{M}$ $\mathrm{H}_{2} \mathrm{SO}_{4}$ solution without and with NMS after 4.0 min relaxation time of the electrodes, in an open circuit. The Nyquist and Bode diagrams were recorded, as shown in Figure 2. The Nyquist diagram (Figure 2a) clearly shows that the increase of the NMS concentration leads to more extensive capacitive loops recording and consequently, the charge-transfer resistance $\left(R_{\mathrm{ct}}\right)$ increases $[4,5,7]$. The presence of neomycin in $1.0 \mathrm{M} \mathrm{H}_{2} \mathrm{SO}_{4}$ solution leads to steel surface changes due to the inhibitor adsorption and, thus, the polarization resistance $\left(R_{\mathrm{ct}}\right)$ increases with the increase of the NMS concentration. The Bode diagram (Figure 2b) shows that the impedance response increases with the increase of the NMS concentration reaching a logarithmic value of 1.27, at an inhibitor concentration of $0.9 \mathrm{mM}$, significantly higher compared to that obtained for the blank acidic solution, when the value of 0.9 was recorded for $\log Z$. Moreover, in the presence of NMS, the phase angle maximum is shifted to lower frequencies compared to the blank, varying from -51.63 degrees in the absence of NMS to -59.67 degrees in its presence. Consequently, the presence of NMS leads to the appearance of a layer which interposes at the metal/electrolyte interface, reducing the corrosion rate of carbon steel in sulfuric acid solution.
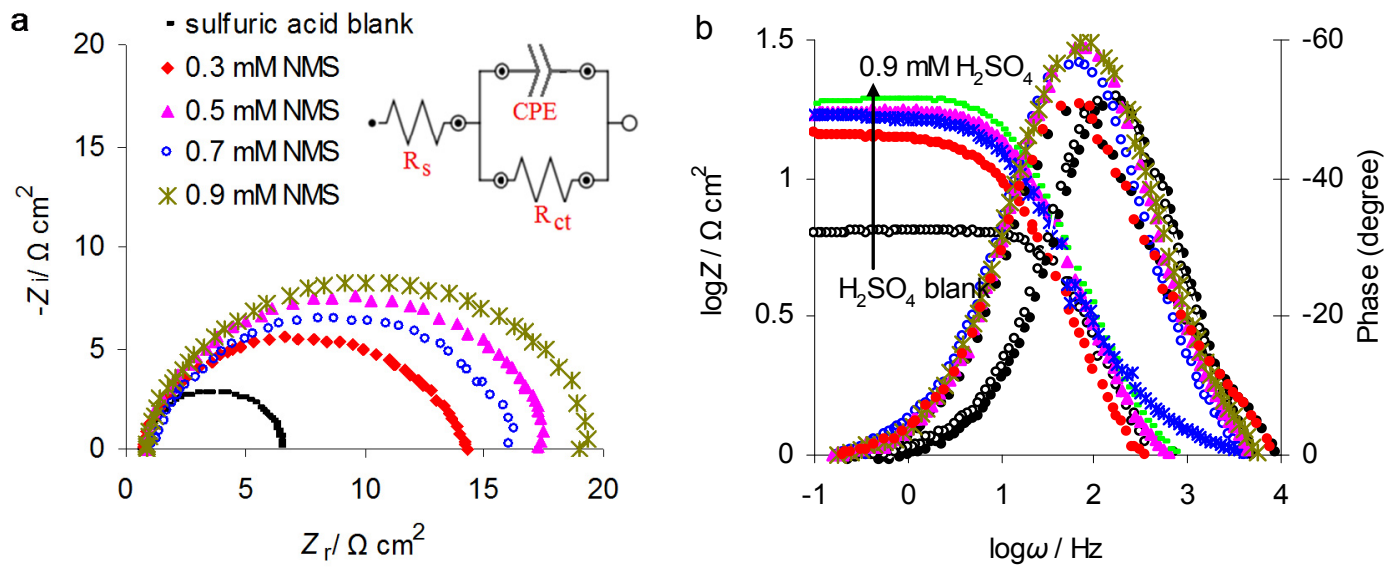

Figure 2. Nyquist (a) and Bode (b) diagrams recorded for carbon steel in $1.0 \mathrm{M} \mathrm{H}_{2} \mathrm{SO}_{4}$ blank solution and in $1.0 \mathrm{M} \mathrm{H}_{2} \mathrm{SO}_{4}$ solution containing various NMS concentrations.

As in other studies [21,22] for the fitting the experimental data, the Randles equivalent circuit (inserted in Figure 2a) was used, where charge-transfer resistance $\left(R_{\mathrm{ct}}\right)$ is linked in a parallel position with the constant phase element $(\mathrm{CPE})$, both being connected in series with the solution resistance $\left(R_{\mathrm{S}}\right)$.

The effect due to the carbon steel surface imperfections is reflected by the CPE [23]. The CPE impedance $\left(Z_{\mathrm{CPE}}\right)$ was calculated using Equation (5) $[23,24]$ :

$$
\mathrm{Z}_{\mathrm{CPE}}=\frac{1}{T(j \omega)^{n}}
$$


where $T$ is a proportional factor; $j$ equals $-1 ; \omega$ represents the angular frequency; and $n$ is the phase shift, between zero and unity, related to the constant phase angle of the CPE. When $n=0, Z_{\mathrm{CPE}}$ corresponds to a resistance with $R=T^{-1}$; if $n=1, Z_{\mathrm{CPE}}$ is a capacitance with $C=T$. When $n$ is closely near 1 , the CPE obeys the capacitive behavior, being assimilated with the double-layer capacitance $\left(C_{\mathrm{dl}}\right)$, as shown in Table 1 .

Similar to potentiodynamic polarization, electrochemical parameters were calculated using the VoltaMaster 4 software, and the results are presented in Table 1 . Additionally, Table 1 shows the inhibition efficiency (IE) calculated as a function of $\left(i_{\text {corr }}\right)$ and $\left(R_{\mathrm{ct}}\right)$, as shown in Equations $(6)$ and $(7)$ [20,23-25]:

$$
\begin{aligned}
& \mathrm{IE}=\frac{i_{\mathrm{corr}}^{0}-i_{\mathrm{corr}}}{i_{\mathrm{corr}}^{0}} \times 100 \\
& \mathrm{IE}=\frac{R_{\mathrm{ct}}-R_{\mathrm{ct}}^{0}}{R_{\mathrm{ct}}} \times 100
\end{aligned}
$$

where $i_{\text {corr }}^{0}$ and $R_{\mathrm{ct}}^{0}$ are the corrosion current density and charge-transfer resistance, respectively computed for the carbon steel corroded in $1.0 \mathrm{M} \mathrm{H}_{2} \mathrm{SO}_{4}$ blank solution; and $i_{\text {corr }}$ and $R_{\mathrm{ct}}$ represent the corrosion current density and charge-transfer resistance, respectively, computed for carbon steel corroded in $1.0 \mathrm{M} \mathrm{H}_{2} \mathrm{SO}_{4}$ solution containing various NMS concentrations.

In Table 1 the IE values obtained by averaging values computed from both potentiodynamic polarization and EIS are presented.

The experimental data listed in Table 1 shows that NMS behaves as a corrosion inhibitor for carbon steel, in $1.0 \mathrm{M} \mathrm{H}_{2} \mathrm{SO}_{4}$ at room temperature. The following arguments support this statement: (i) the increase of the NMS concentration leads to $i_{\text {corr }}$ breakdown while $R_{\mathrm{ct}}$ increases and $C_{\mathrm{dl}}$ decreases; (ii) IE follows the same increasing trend as the inhibitor concentration; and (iii) the NMS inhibition action is due to the adsorption of its molecules on carbon steel surface, contributing to the formation of a surface protective layer [23-26].

\subsection{NMS Adsorption Mechanism}

The adsorption can be quantitatively expressed by applying adsorption isotherms. The fitting of the degree of surface coverage $(\theta)$ values with the maximum regression coefficient $\left(R^{2}\right)$ enables the accurate determination of the adsorption-desorption equilibrium constant $(K)$, and then the calculation of the standard adsorption free energy $\left(\Delta G_{\text {ads }}^{0}\right)[20-28]$.

In our study, the experimental data were successfully fitted by applying the Langmuir adsorption isotherm (Figure 3a), its linearized form being expressed by Equation (8) [27]:

$$
\frac{\theta}{1-\theta}=K \cdot C
$$

where $C$ is the NMS concentration (M) in the bulk electrolyte; $\theta$ is the average value of the degree of surface coverage, being calculated as IE/100; $K$ is the adsorption-desorption equilibrium constant.

By plotting $\theta /(1-\theta)$ as a function of $C$, the straight line was obtained with the slope equal to $K$ (3379.1 L.mol ${ }^{-1}$ ) and the $R^{2}$ value of 0.97. Equation (9) was used to determine the standard adsorption free energy $\left(\Delta G_{\text {ads }}^{0}\right)[26,27]$ :

$$
\Delta G_{\text {ads }}^{0}=R T[\ln (1 / 55.5)-\ln K]
$$

where $R$ is the universal constant of gases $\left(8.31 \mathrm{~J} \cdot \mathrm{mol}^{-1} \cdot \mathrm{K}^{-1}\right), T$ is the temperature $(298 \mathrm{~K})$ and 55.5 is the value of the molar concentration of water in the solution.

The $\Delta G_{\text {ads }}^{0}$ value of $-30.06 \mathrm{~kJ} \cdot \mathrm{mol}^{-1}$ certifies a spontaneous moderate adsorption of NMS molecules on the carbon steel surface.

To appreciate the type of adsorption as physisorption or chemisorption the binding energy (BE) of the adsorbate to the substrate can be determined [5]. Thus, knowing that $1.0 \mathrm{~kJ} \cdot \mathrm{mol}^{-1}$ is equal to $1.04 \times 10^{-2} \mathrm{eV} /$ molecule, it can be observed that the binding energy of neomycin molecule reaches the 
value of $0.31 \mathrm{eV}$. This is higher than the typical binding energy of physisorption that ranges between $0.01 \mathrm{eV}$ and $0.1 \mathrm{eV}$, but less than that corresponding to chemisorption when, usually, the binding energy varies from $1.0 \mathrm{eV}$ to $10.0 \mathrm{eV}$. Consequently, there is a synergism between the physical and chemical adsorption and consequently, adsorption mixed mechanism of the neomycin molecules on the carbon steel surface takes place. Based on the molecular structure of the inhibitor (Figure 3b), it can be observed that the adsorption of NMS molecules on carbon steel surface can be achieved by: (1) weak bonds between the neomycin molecules and carbon steel surface, suggesting physical adsorption which leaves the chemical species intact; (2) stronger interaction between the neomycin molecules and the carbon steel surface involving bonds between the unshared electron pairs from the oxygen and nitrogen atoms and $d$-vacant orbital of iron from metal surface, indicating chemical adsorption; and (3) additionally, the complexes of neomycin-iron ions [19] can be adsorbed onto the steel surface through Van der Waals bonds [5].

Neomycin sulfate is a particular aminoglycoside antibiotic being the mixture of two stereoisomers as neomycin B (main product presented in Figure $3 \mathrm{~b}$ ) and neomycin C, less than $3.0 \%[29,30]$. Acid hydrolysis of neomycin $B$ yields neamine and neobiosamine $B$, and the hydrolysis of neomycin $C$ leads to neamine and neobiosamine $C$ [30]. Neobiosamine $B$ and $C$ are composed of D-ribose and neosamine $\mathrm{B}$ and $\mathrm{C}$, respectively [30]. To elucidate the neomycin behavior, UV-Vis spectrophotometry of $1.0 \mathrm{M} \mathrm{H}_{2} \mathrm{SO}_{4}$ solution containing $0.9 \mathrm{mM}$ neomycin was performed. The UV-Vis scans before and after potentiodynamic polarization are illustrated in Figure 4.
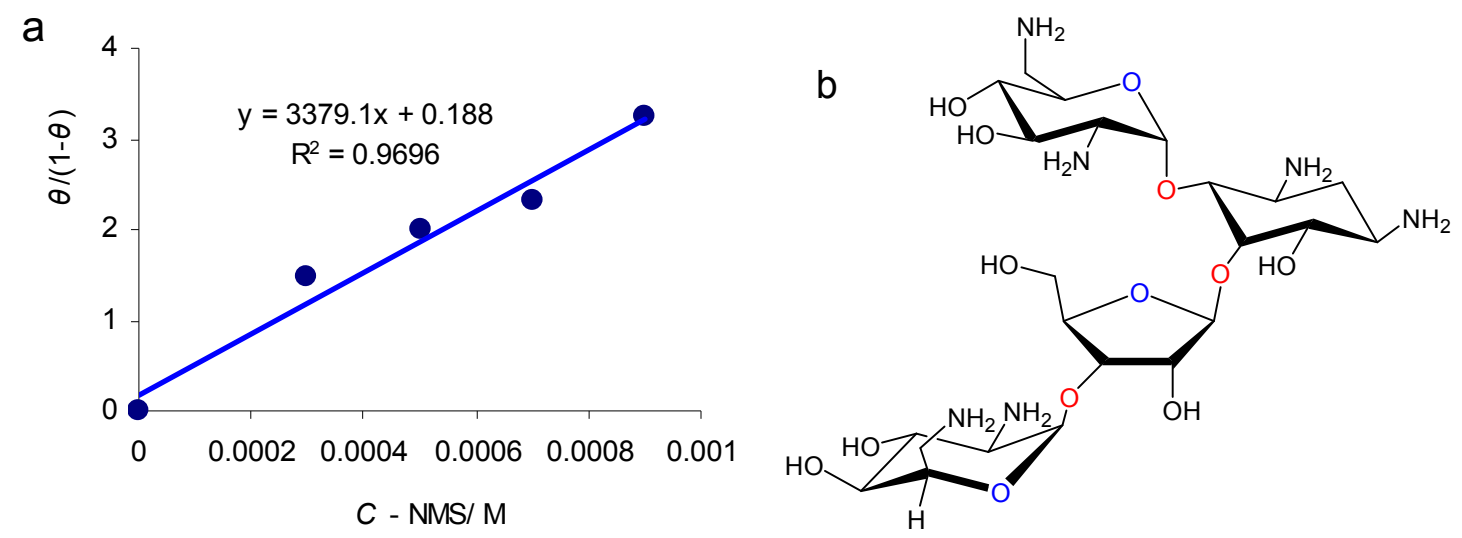

Figure 3. Langmuir diagram (a) corresponding to neomycin adsorption on carbon steel surface in 1.0 $\mathrm{M} \mathrm{H}_{2} \mathrm{SO}_{4}$-inhibited solution and the molecular structure of neomycin $\mathrm{B}(\mathbf{b})$.

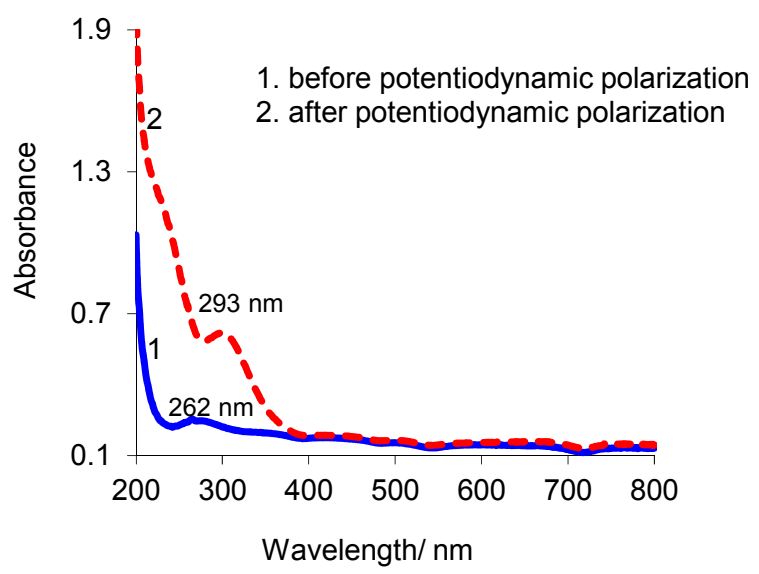

Figure 4. The UV-Vis scans of $1.0 \mathrm{M} \mathrm{H}_{2} \mathrm{SO}_{4}$ solution containing $0.9 \mathrm{mM}$ neomycin recorded before and after potentiodynamic polarization. 
Before the potentiodynamic polarization, the UV-Vis spectrum shows an absorption maximum centered around $262.0 \mathrm{~nm}$; it starts at $312.0 \mathrm{~nm}$ and extends up to $235.0 \mathrm{~nm}$. The UV-Vis spectrum of neomycin in bi-distilled water solvent showed an adsorption maximum at wavelength, $\lambda_{\max }$ of $304.8 \mathrm{~nm}$ [31]. Consequently, in $1.0 \mathrm{M} \mathrm{H}_{2} \mathrm{SO}_{4}$ solution certain interferences with neomycin occur leading to the results above mentioned. After potentiodynamic polarization, a completely different spectrum was recorded. A peak highlighted at 293.0 (beginning from $360.0 \mathrm{~nm}$ and ending to $260.0 \mathrm{~nm}$ ) is followed by an extended loop from $267.0 \mathrm{~nm}$ to $220.0 \mathrm{~nm}$. These results suggest the environment composition changing, after potentiodynamic measurements, by the appearance of other chemical species formed by the inhibitor decomposition reaction, interfering with neomycin around $293.0 \mathrm{~nm}$. Thus, the concentration of neomycin decreases causing the alteration of its spectrum, but in the same time the absorbance increases due to the appearance of new chemical species. According to literature data, the main decomposition compounds consist of neamine and neobiosamine [30]. The neomycin B electrochemical decomposition mechanism is proposed, as shown in Scheme 1.

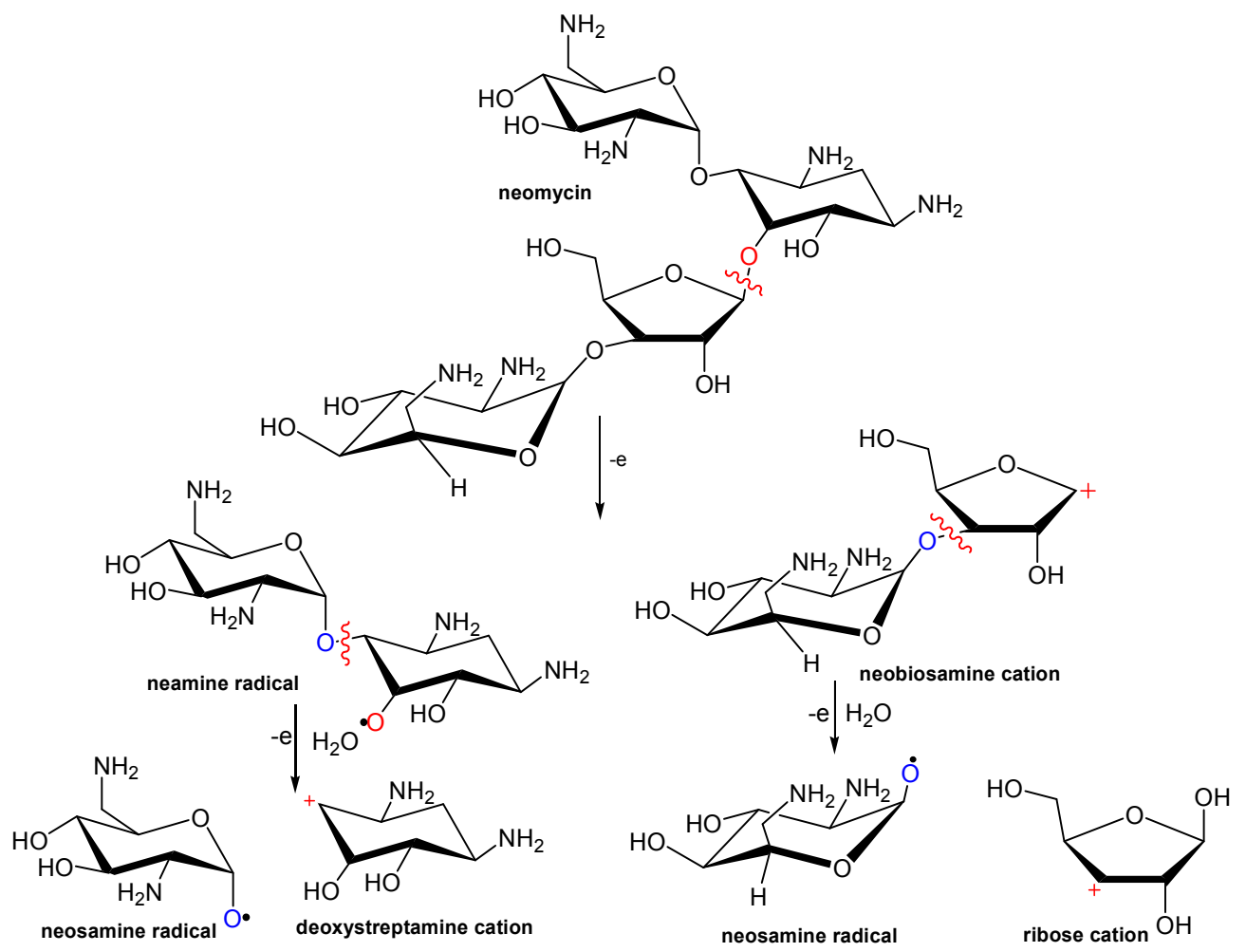

Scheme 1. The decomposition mechanism of neomycin B.

Neomycin exhibits relative stability during potentiodynamic polarization. In acidic aqueous environments and high values of anode voltage, the etheric bridges between the aminoglycoside cycles may be cleaved with the formation of neamine and neobiosamine as main compounds and a mixture of other monocyclic species, leading to the composition of the corrosive environment changing (Scheme 1). Thus, during potentiodynamic measurements, adsorbed molecules of neomycin and its electrochemical degradation compounds can occur on the carbon steel surface, involving the composition modification of the surface upper-layer.

The action mechanism of neomycin as corrosion inhibitor of carbon steel in $1.0 \mathrm{M} \mathrm{H}_{2} \mathrm{SO}_{4}$ solution is more complex than that reported for 304 stainless steel that involved physisorption and other interactions [17], inhibitor performance being attributed to strong adsorption of nitrogen atoms [17]. It is known that the 304 stainless steel has a composition and surface characteristics different from those of carbon steel. 


\subsection{Atomic Force Microscopy (AFM) Technique}

The NMS addition in $1.0 \mathrm{M} \mathrm{H}_{2} \mathrm{SO}_{4}$ solution modified the morphology and topography of the carbon steel surface, as shown by AFM, based on the examination at nano-level of metal surfaces [32], which is displayed in Figure 5. This figure illustrates the 2D and 3D images of carbon steel surfaces, before and after potentiodynamic polarization in $1.0 \mathrm{M} \mathrm{H}_{2} \mathrm{SO}_{4}$ solution uninhibited and inhibited with $0.9 \mathrm{mM}$ neomycin. Both 2D and 3D images highlight the major change of surface morphology of carbon steel corroded in sulfuric acid without (Figure 5b) and with NMS (Figure 5c) compared to that exhibited for the standard sample (Figure 5a). Figure 5a shows the specific surface of the standard sample, which was initially subjected to a characteristic mechanical processing.

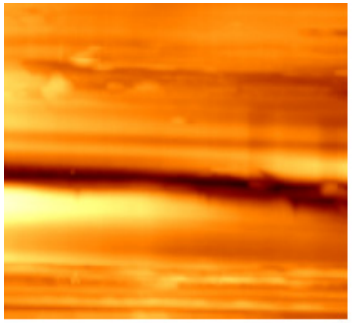

a

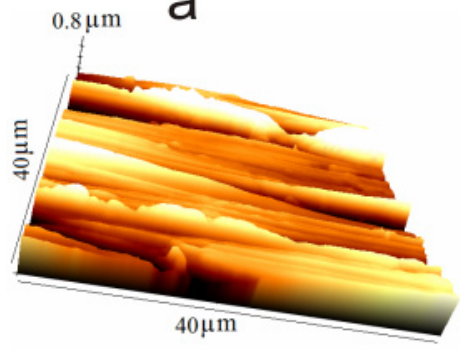

Figure 5. 2D and 3D AFM images obtained for carbon steel surface: (a) before corrosion (control sample); (b) after potentiodynamic polarization of carbon steel in $1.0 \mathrm{M} \mathrm{H}_{2} \mathrm{SO}_{4}$ solution in the absence of the inhibitor; and (c) after potentiodynamic polarization of carbon steel in $1.0 \mathrm{M} \mathrm{H}_{2} \mathrm{SO}_{4}$ solution containing $0.9 \mathrm{mM}$ neomycin.

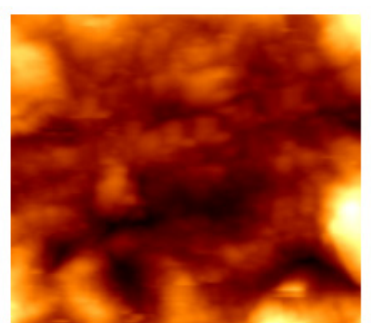

b
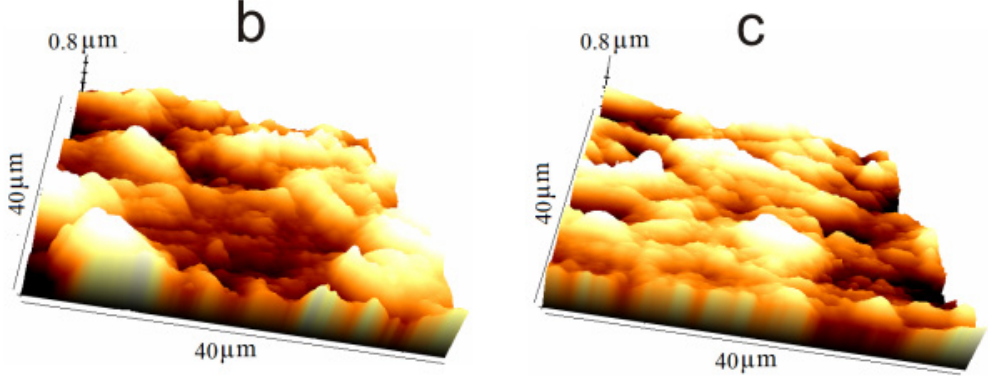

In the absence of the inhibitor (Figure 5b), the surface layer is uneven and strongly affected areas that occurred during corrosion are highlighted. In contrast, the surface layer of carbon steel corroded in the presence of NMS (Figure 5c) is more uniform, suggesting that the neomycin adsorbed molecules contributed to the surface protective layer formation.

The AFM parameters, such as $R_{\mathrm{q}}$, root mean square (RMS) roughness; $R_{\mathrm{a}}$, average roughness; and $R_{\mathrm{p}-\mathrm{v}}$, maximum peak to valley height are presented in Table 2.

Table 2. AFM roughness parameters obtained for carbon steel uncorroded and corroded in saline blank solution and in saline blank solution containing $0.9 \mathrm{mM}$ neomycin.

\begin{tabular}{cccc}
\hline Sample & $\boldsymbol{R}_{\mathbf{q}} / \mathbf{n m}$ & $\boldsymbol{R}_{\mathbf{a}} / \mathbf{n m}$ & $\boldsymbol{R}_{\mathbf{p}-\mathbf{v}} / \mathbf{n m}$ \\
\hline Carbon steel, control sample & 125.1 & 95.6 & 647.4 \\
Carbon steel/1.0 $\mathrm{M} \mathrm{H}_{2} \mathrm{SO}_{4}$ & 397.0 & 308.0 & 1634.0 \\
Carbon steel/1.0 $\mathrm{M} \mathrm{H}_{2} \mathrm{SO}_{4} / 0.9 \mathrm{mM}$ NMS & 170.1 & 127.1 & 896.6 \\
\hline
\end{tabular}

As expected, the smallest parameters were obtained for the standard sample. In the absence of NMS, the higher values for $R_{\mathrm{a}}, R_{\mathrm{q}}$, and $R_{\mathrm{p}-\mathrm{v}}$ were obtained, indicating that the surface morphology and roughness changed [32,33]. In the presence of the NMS inhibitor, the values of the AFM parameters 
decreased, indicating a smoother surface compared to that of carbon steel corroded in blank solution, but higher than that of the standard sample.

Consequently, NMS behaves as corrosion inhibitor for carbon steel in $1.0 \mathrm{M} \mathrm{H}_{2} \mathrm{SO}_{4}$, reaching an inhibition efficiency value of $76.4 \%$, at a concentration of $0.9 \mathrm{mM}$. The interaction process of neomycin molecules with the carbon steel surface takes place by a mixed mechanism of spontaneous physical and chemical adsorption. The inhibitor electrochemical degradation compounds contribute to the protective layer formation that restricts the corrosion processes.

It is noted that drugs have a significant inhibitory performance, most of them reaching efficiency greater than $75.0 \%$, depending on their concentration in the tested environment, type of steel, electrolyte composition, and $\mathrm{pH}$, temperature, etc. [19,27].

In our previous studies, for the same type of carbon steel and under the same laboratory conditions, we reported an inhibition efficiency of $93.6 \%$ for quinine sulfate, at $0.4 \mathrm{mM}$ in $1.5 \mathrm{M} \mathrm{HCl}$ solution [4], $92 \%$ for trimethoprim [2], and $87.3 \%$ for aminophylline [5], at $0.9 \mathrm{mM}$ and $0.6 \mathrm{mM}$, respectively, in $1.0 \mathrm{M} \mathrm{HCl}$ solution. Moreover, the metronidazole inhibition performance in $1.0 \mathrm{M} \mathrm{HCl}$ solution was investigated for different substrates, when at an inhibitor concentration of $0.8 \mathrm{mM}$, the inhibition efficiency reached $67.9 \%$ for $304 \mathrm{~L}$ stainless steel [23], around $80.0 \%$ for carbon steel [23] and copper [14], and $88.3 \%$ for aluminum [23].

The vanillin food additive tested as corrosion inhibitor for carbon steel in $10^{-3} \mathrm{M} \mathrm{HCl}$ solution containing $8.0 \mathrm{mM}$ inhibitor reached an inhibition efficiency of $83.1 \%$ [34].

The amino-acids inhibition efficiency for the $316 \mathrm{~L}$ stainless steel corrosion in $1.0 \mathrm{M} \mathrm{H}_{2} \mathrm{SO}_{4}$ containing $0.1 \mathrm{M}$ inhibitor ranged as follows: glycine $(84.2 \%)>$ valine $(38.2 \%)>$ leucine $(33.5 \%)$ [35]. All of these inhibitors acted by adsorption on substrates, blocking the surface active sites.

\section{Conclusions}

Neomycin sulfate was investigated as an inhibitor for carbon steel corrosion in $1.0 \mathrm{M} \mathrm{H}_{2} \mathrm{SO}_{4}$ solution, using potentiodynamic polarization and electrochemical impedance spectroscopy associated with AFM.

The electrochemical measurements showed that in the presence of the inhibitor the corrosion current density decreased, while polarization resistance increased. Consequently, the inhibition efficiency increased with the increase of the inhibitor concentration, reaching an average value of $76.4 \%$, at $0.9 \mathrm{mM}$ neomycin concentration.

The experimental data were fitted according to the Langmuir adsorption isotherm, from which the adsorption-desorption equilibrium constant $(K)$ value of $3379.1 \mathrm{~L} \cdot \mathrm{mol}^{-1}$ was calculated. The standard adsorption free energy $\left(\Delta G_{\text {ads }}^{0}\right.$ ) of $-30.06 \mathrm{~kJ} \cdot \mathrm{mol}^{-1}$ was obtained and, consequently, a mixed mechanism for spontaneous adsorption of neomycin molecules was proposed as the synergism between physical and chemical adsorption, with the first prevailing.

The surface protective layer composition mainly consists from neomycin and a mixture of its derivative compounds and complexes of inhibitor-iron ions, inclusively.

AFM confirmed that the neomycin adsorbed molecules on the carbon steel surface contributed to the occurrence of a more uniform protective layer than that formed in the absence of the inhibitor.

Acknowledgments: The funding of this work was supported by the research grants awarded by the University of Craiova, Romania, in the competition "The Awards of Research Results-ISI Articles", April 2017.

Author Contributions: Adriana Samide conceived and designed the experiments; Roxana Grecu and Bogdan Tutunaru performed the electrochemical measurements; Gabriela Eugenia Iacobescu performed the AFM analysis; Adriana Samide, Bogdan Tutunaru, and Gabriela Eugenia Iacobescu wrote the paper; and Cristian Tigae and Cezar Spînu contributed with reagents, materials, analysis tools, and software. All authors read the article and critically reviewed it.

Conflicts of Interest: The authors declare no conflict of interest. 


\section{References}

1. Guo, L.; Obot, I.B.; Zheng, X.; Shen, X.; Qiang, Y.; Kaya, S.; Kaya, C. Theoretical insight into an empirical rule about organic corrosion inhibitors containing nitrogen, oxygen, and sulfur atoms. Appl. Surf. Sci. 2017, 406, 301-306. [CrossRef]

2. Samide, A. A pharmaceutical product as corrosion inhibitor for carbon steel in acidic environments. J. Environ. Sci. Health 2013, 48, 159-165. [CrossRef] [PubMed]

3. Aziz, R.J. Study of some drugs as corrosion inhibitors for mild steel in $1 \mathrm{M} \mathrm{H}_{2} \mathrm{SO}_{4}$ solution. Int. J. Curr. Res. Chem. Pharm. Sci. 2016, 3, 1-7. [CrossRef]

4. Samide, A.; Tutunaru, B. Quinine sulfate: A pharmaceutical product as effective corrosion inhibitor for carbon steel in hydrochloric acid solution. Cent. Eur. J. Chem. 2014, 12, 901-908. [CrossRef]

5. Samide, A.; Tutunaru, B.; Ionescu, C.; Rotaru, P.; Simoiu, L. Aminophylline: Thermal characterization and its inhibitory properties for the carbon steel corrosion in acidic environment. J. Therm. Anal. Calorim. 2014, 118, 631-639. [CrossRef]

6. Samide, A.; Tutunaru, B.; Negrilă, C.; Trandafir, I.; Maxut, A. Effect of sulfacetamide on the corrosion products formed onto carbon steel surface in hydrochloric acid. Dig. J. Nanomater. Biostruct. 2011, 6, 663-673.

7. Samide, A.; Tutunaru, B.; Negrilă, C. Corrosion inhibition of carbon steel in hydrochloric acid solution using a sulfa drug. Chem. Biochem. Eng. Q. 2011, 25, 299-308.

8. Samide, A.; Tutunaru, B.; Negrilă, C.; Prunaru, I. Surface analysis of inhibitor film formed by 4-amino-N-(1,3-thiazol-2-yl) benzene sulfonamide on carbon steel surface in acidic media. Spectrosc. Lett. 2012, 45, 55-64. [CrossRef]

9. Gupta, N.K.; Gopal, C.S.A.; Srivastava, V.; Quraishi, M.A. Application of expired drugs in corrosion inhibition of mild steel. Int. J. Pharm. Chem. Anal. 2017, 4, 8-12.

10. Gopiraman, M.; Sakunthala, P.; Kesavan, D.; Alexramani, V.; Kim, I.S.; Sulochana, N. An investigation of mild carbon steel corrosion inhibition in hydrochloric acid medium by environment friendly green inhibitors. J. Coat. Technol. Res. 2012, 9, 15-26. [CrossRef]

11. Zhu, G.; Hou, J.; Zhu, H.; Qiu, R.; Xu, J. Electrochemical synthesis of poly(3,4-ethylenedioxythiophene) on stainless steel and its corrosion inhibition performance. J. Coat. Technol. Res. 2013, 10, 659-668. [CrossRef]

12. Palimi, M.J.; Rostami, M.; Mahdavian, M.; Ramezanzadeh, B. A study on the corrosion inhibition properties of silane-modified $\mathrm{Fe}_{2} \mathrm{O}_{3}$ nanoparticle on mild steel and its effect on the anticorrosion properties of the polyurethane coating. J. Coat. Technol. Res. 2015, 12, 277-292. [CrossRef]

13. Dolabella, L.M.P.; Oliveira, J.G.; Lins, V.; Matencio, T.; Vasconcelos, W.L. Ethanol extract of propolis as a protective coating for mild steel in chloride media. J. Coat. Technol. Res. 2016, 13, 543-555. [CrossRef]

14. Samide, A.; Tutunaru, B.; Dobrițescu, A.; Ilea, P.; Vladu, A.C.; Tigae, C. Electrochemical and theoretical study of metronidazole drug as inhibitor for copper corrosion in hydrochloric acid solution. Int. J. Electrochem. Sci. 2016, 11, 5520-5534. [CrossRef]

15. Karthikeyan, S. Drugs/Antibiotics as potential corrosion inhibitors for metals-A review. Int. J. ChemTech Res. 2016, 9, 251-259.

16. Xhanari, K.; Finsgar, M.; Hrncic, M.K.; Maver, U.; Knez, Z.; Seiti, B. Green corrosion inhibitors for aluminium and its alloys: A review. RSC Adv. 2017, 7, 27299-27330. [CrossRef]

17. Raja, K.; Jeeva, P.A.; Karthikeyan, S. Reduction of hydrogen embrittlement and green inhibition of stainless steel pipes in acid environment. Int. J. ChemTech. Res. 2015, 7, 2425-2431.

18. Fouda, A.S.; Elmorsi, M.A.; Fayed, T.A.; Hassan, A.F.; Soltan, M. Corrosion inhibitors based on antibiotic derivatives for protection of carbon steel corrosion in hydrochloric acid solutions. Int. J. Adv. Res. 2014, 2, 788-807.

19. Chitra, S.; Anand, B. Surface morphological and FTIR spectroscopic information on the corrosion inhibition of drugs on mild steel in chloride environment. J. Chem. Pharm. Sci. 2017, 10, 453-456.

20. Zerga, B.; Attayibat, A.; Sfaira, M.; Taleb, M.; Hammouti, B.; Ebn Touhami, M.; Radi, S.; Rais, Z. Effect of some tripodal bipyrazolic compounds on C38 steel corrosion in hydrochloric acid solution. J. Appl. Electrochem. 2010, 40, 1575-1582. [CrossRef]

21. Sobhi, M. Gatitloxacin as corrosion inhibitor for carbon steel in hydrochloric acid solutions. Prot. Met. Phys. Chem. Surf. 2014, 50, 825-883. [CrossRef] 
22. Abdallah, M.; Jahdaly, B.A.AL. Gentamicin, kanamycin and amikacin drugs as non-toxic inhibitors for corrosion of aluminium in 1.0 M hydrochloric acid. Int. J. Electrochem. Sci. 2015, 10, 9808-9823.

23. Samide, A.; Ilea, P.; Vladu, A.C. Metronidazole performance as corrosion inhibitor for carbon steel, 304L stainless steel and aluminium in hydrochloric acid solution. Int. J. Electrochem. Sci. 2017, 12, 5964-5983. [CrossRef]

24. Bobina, M.; Kellenberger, A.; Millet, J.P.; Muntean, C.; Vaszilcsin, N. Corrosion resistance of carbon steel in weak acid solutions in the presence of l-histidine as corrosion inhibitor. Corros. Sci. 2013, 69, 389-395. [CrossRef]

25. Nazeer, A.A.; El-Abbasy, H.M.; Fouda, A.S. Adsorption and corrosion inhibition behavior of carbon steel by cefoperazone as eco-friendly inhibitor in HCl. J. Mater. Eng. Perform. 2013, 22, 2314-2322.

26. Fouda, A.S.; Mostafa, H.A.; El-Abbasy, H.M. Antibacterial drugs as inhibitors for the corrosion of stainless steel type 304 in $\mathrm{HCl}$ solution. J. Appl. Electrochem. 2010, 40, 163-173. [CrossRef]

27. Samide, A.; Bibicu, I. Kinetics corrosion process of carbon steel in hydrochloric acid in absence and presence of 2-(cyclohexylaminomercapto) benzothiazole. Surf. Interface Anal. 2008, 40, 944-952. [CrossRef]

28. Samide, A.; Rotaru, P.; Ionescu, C.; Tutunaru, B.; Moanţă, A.; Barragan-Montero, V. Thermal behaviour and adsorption properties of some benzothiazole derivatives. J. Therm. Anal. Calorim. 2014, 118, 651-659. [CrossRef]

29. Clarot, I.; Regazzeti, A.; Auzeil, N.; Laadani, F.; Citton, M.; Netter, P.; Nicolas, A. Analysis of neomycin sulfate and framycetin sulfate by high-performance liquid chromatography using evaporative light scattering detection. J. Chromatogr. A 2005, 1087, 236-244. [CrossRef] [PubMed]

30. Hanko, V.P.; Rohrer, J.S. Determination of neomycin sulfate and impurities using high-performance anion-exchange chromatography with integrated pulsed amperometric detection. J. Pharm. Biomed. 2007, 43, 131-141. [CrossRef] [PubMed]

31. Abraha, A.; Gholap, A.V.; Belay, A. Study self-association, optical transition properties and thermodynamic properties of neomycin sulfate using UV-Visible spectroscopy. Int. J. Biophys. 2016, 6, 16-20.

32. Geetha, M.B.; Rajendran, S. Synergistic Inhibition of Corrosion of Mild Steel in Sulphuric acid by New Ternary System. Der. Pharm. Chem. 2016, 8, 194-201.

33. Samide, A.; Iacobescu, G.E.; Tutunaru, B.; Tigae, C. Electrochemical and AFM study of inhibitory properties of thin film formed by tartrazine food additive on $304 \mathrm{~L}$ stainless steel in saline solution. Int. J. Electrochem. Sci. 2017, 12, 2088-2101. [CrossRef]

34. Samide, A.; Tutunaru, B. Eurovanillin thermal behaviour and its inhibitory properties on carbon steel corrosion in weakly acidic environments. J. Therm. Anal. Calorim. 2017, 127, 863-870. [CrossRef]

35. Abdel Ghanyl, N.A.; El-Shenawy, A.E.; Hussien, W.A.M. The Inhibitive effect of some amino acids on the corrosion behaviour of 316L stainless steel in sulfuric acid solution. Mod. Appl. Sci. 2011, 5, 19-29. 